\title{
CDK4/6 inhibitors have potent activity in combination with pathway selective therapeutic agents in models of pancreatic cancer
}

\author{
Jorge Franco ${ }^{1}$, Agnieszka K. Witkiewicz ${ }^{1,2}$ and Erik S. Knudsen ${ }^{1,2}$ \\ ${ }^{1}$ Department of Pathology, UT Southwestern, Dallas TX \\ ${ }^{2}$ Simmons Cancer Center, UT Southwestern, Dallas TX \\ Correspondence to: Erik S. Knudsen, email: Erik.knudsen@utsouthwestern.edu \\ Agnieszka K.Witkiewicz, email: Agnes.Witkiewicz@utsouthwestern.edu \\ Keywords: RB, CDK4/6, palbocicllb, pancreatic cancer, E2F \\ Received: July 10, $2014 \quad$ Accepted: July 26, $2014 \quad$ Published: July 26, 2014
}

This is an open-access article distributed under the terms of the Creative Commons Attribution License, which permits unrestricted use, distribution, and reproduction in any medium, provided the original author and source are credited.

\section{ABSTRACT}

Pancreatic ductal adenocarcinoma (PDA) has a poor prognosis, in part, due to the therapy-recalcitrant nature of the disease. Loss of the CDK4/6 inhibitor CDKN2A is a signature genetic event in PDA. Therefore, PDA may be amenable to treatment with pharmaceutical CDK4/6 inhibitors. Surprisingly, response to CDK4/6 inhibition was highly variable in PDA models, and was associated with differential suppression of RBregulated gene expression. Mitotic genes were repressed and FOXM1 was uniformly attenuated; however, genes involved in DNA replication were uniquely suppressed in sensitive models. Aberrant induction of Cyclin E1 was associated with resistance, and knockdown demonstrated synergistic suppression of the cell cycle with CDK4/6 inhibition. Combination therapies are likely required for the effective treatment of disease, and drug screening demonstrated additive/antagonistic interactions with CDK4/6 inhibitors. Agents dependent on mitotic progression (taxanes/PLK1 inhibitors) were antagonized by CDK4/6 inhibition, while the response to 5-FU and gemcitabine exhibited drug specific interactions. PI3K/MTOR and MEK inhibitors potently cooperated with CDK4/6 inhibition. These agents were synergistic with CDK4/6 inhibition, blocked the aberrant upregulation of Cyclin E1, and yielded potent inhibition of tumor cell growth. Together, these data identify novel mechanisms of resistance to CDK4/6 inhibitions and provide a roadmap for combination therapies in the treatment of PDA.

\section{INTRODUCTION}

Pancreatic ductal adenocarcinoma (PDA) has a poor prognosis with a 5 -year survival of approximately $6 \%$ [1-3]. The approved systemic therapies have a relatively modest impact on survival, and PDA is considered a therapy recalcitrant disease $[1,2,4]$. Interestingly, the treatment of PDA has remained largely dependent on the use of systemic chemotherapy regimens, and there are basically no targeted approaches to treatment that exploit the underlying genetic features of pancreatic cancer. PDA is largely driven by oncogenic events (e.g. KRAS), which historically are considered "non-actionable" from a therapeutic perspective. However, PDA exhibits a range of genetic alterations, some of which could be amenable to targeted therapy. One of these alterations is the genetic loss or epigenetic silencing of the CDKN2A tumor suppressor [5-8].

The CDKN2A gene encodes the p16ink4a protein that is a potent inhibitor of Cyclin Dependent Kinases 4 and $6(\mathrm{CDK} 4 / 6)$. Physiologically, p16ink4a represents a key barrier to oncogenic transformation, as it is induced by oncogenic stress and leads to senescence in multiple disease relevant settings [9]. In the context of PDA, it has been hypothesized that p16ink4a loss is selected for to enable the progression of KRAS mutated cells [10-13]. Correspondingly, it has been shown that the over-expression of p16ink4a is dominant to the effects 
of KRAS in cell culture models and is capable of reestablishing a senescence-like arrest in established cancer models [14-17]. The only known functional target of p16ink4a are the kinases CDK4 and CDK6 [9, 18-23]. p16ink4a-mediated arrest is selectively bypassed by CDK4 mutations that disrupt the association with the inhibitor [24, 25]. Similarly, loss of RB, which is the down stream target for CDK4/6 bypasses the growth inhibitory activity of p16ink4a [9, 26]. Furthermore, analysis of mutual-exclusivity in cancer demonstrates that there is a pronounced reciprocal relationship between the loss of p16ink4a, deregulation of CDK4/6, and loss of RB [25, $27,28]$. Thus these events describe a single pathway, wherein the predominant event occurring in PDA is loss of p16ink4a, and suggest that restoring its biological function could represent a key means to limit the growth of KRAS driven cancers.

While multiple CDK-inhibitory agents have been evaluated in clinical trials, only recently have highly specific CDK4/6 inhibitory drugs been developed [29, 30]. Consistent with the function of p16ink4a, they induce a highly potent G1-arrest that is dependent on the suppression of CDK $4 / 6$ and the presence of $\mathrm{RB}$ tumor suppressor (RB) [31-33]. RB is a critical downstream effector of CDK4/6 and regulates the expression of a host of target genes through interactions with E2F and other transcription factor complexes [34]. These targets include CDK/Cyclin subunits (e.g. Cyclin E and Cyclin A), DNA replication factors (e.g. MCM7 and PCNA), genes involved in dNTP metabolism (e.g. thymidylate synthase and ribonucleotide reductase), and mitotic progression (e.g. PLK1 and CDC20). In preclinical models, activation of $\mathrm{RB}$ via CDK4/6 inhibition can induce senescent-like arrest [29, 30, 35-39]. An important parallel effector of CDK4/6 is FOXM1, which is stabilized by direct CDK4/6 mediated phosphorylation and stimulates expression of cell cycle regulated genes [40, 41]. Recently, clinical studies have demonstrated that CDK4/6 inhibitors can have potent single agent activity in select tumor models ostensibly addicted to kinase activity, such as liposarcoma and mantle cell lymphoma [42-45]. Additionally, in breast cancer CDK4/6 inhibitors have demonstrated highly significant activity in combination with endocrine agents [46-50]. However, it is also clear that there are features of tumor behavior that we do not fully understand, as other diseases, which frequently lose p16ink4a had minimal response to CDK4/6 inhibitors in the clinic [44, 45].

Here we find that CDK4/6 inhibition can have a potent impact on PDA models. While some models exhibit a durable response, acquired/intrinsic resistance can bypass the action of CDK4/6 inhibition in the majority of models analyzed via a novel mechanism involving induction of Cyclin E1. Drug screening reveals a complex and mechanism specific impact of CDK4/6 inhibitors on drug-sensitivity. However, specific combination therapies clearly expand the therapeutic potency of CDK4/6 inhibition for the treatment of PDA.

\section{RESULTS}

\section{CDKN2A-deficient PDA models exhibit differential response to $\mathrm{CDK} 4 / 6$ inhibition}

Eight pancreatic cancer cell lines were screened for their proliferative response to CDK4/6 inhibition. In addition to multiple PDA signature mutations (e.g. KRAS, SMAD4, and TP53) these cell lines carried a non-functional CDKN2A gene (Fig. 1A). In order to test sensitivity to CDK4/6 inhibitors, cells were treated with increasing concentrations of PD-0332991, and proliferation was measured by 5-bromo-2-deoxyuridine (BrdU) incorporation (Fig. 1B). Results showed that some model experienced a complete suppression of proliferation (e.g. CAPAN2), while others were modestly or mostly resistant to CDK4/6 inhibitor (e.g. HS766T and PL5). Recognizing that PDA cell lines display differential proliferative responses to acute treatment, long-term treatment responses were also monitored in order to evaluate if the responses are maintained over time (Fig 1C). CAPAN2 cells being the most sensitive to the acute treatment, also exhibited significant suppression of proliferation with long-term treatment. In contrast, cell proliferation occurred in PL45, ASPC1 and PL5, albeit at a reduced extent relative to control. These results indicate that there is differential proliferative response to $\mathrm{CDK} 4 / 6$ inhibition within $\mathrm{CDKN} 2 \mathrm{~A}$ deficient PDA cell models, and suggests that there are additional determinants of therapeutic sensitivity. A possible explanation of these results is that in resistant models the phosphorylation of $\mathrm{RB}$ is $\mathrm{CDK} 4 / 6$ independent. In analysis of RB phosphorylation by mobility shift and with phospho-specific antibodies, CDK4/6 inhibition did suppress the phosphorylation of RB across all models interrogated (Fig 1D). These results were confirmed by reverse phase protein array (RPPA) analysis, wherein RB dephosphorylation was the only consistently observed change amongst 53 phosphoproteins analyzed (not shown). Thus, from conventional assessment of the RBpathway, CDK4/6 inhibitors should be actionable.

\section{PDA models exhibit distinct suppression of E2F gene expression with CDK4/6 inhibition}

To interrogate the downstream signaling from CDK4/6 inhibition, we analyzed the expression of RB/E2F target genes using a high-density RBTARGET Affymetrix array (probes listed in supplemental tables). Using a 2-fold cutoff and $\mathrm{p}<0.05$ we found that there were many $\mathrm{RB} / \mathrm{E} 2 \mathrm{~F}$ targets genes that were repressed potently with CDK4/6 inhibition (Fig. 2A). Specifically, a large number of genes 
were repressed in CAPAN2 cells that exhibit a durable response to CDK4/6 inhibition. In contrast, the PL45 and PL5 cell lines exhibited modest suppression of such genes (Fig. 2B). Interestingly, by gene ontology analyses these groups of genes segregated along biological processes (Fig. 2C). There was potent suppression of mitotic genes across cell models with CDK4/6 inhibition; however, the suppression of DNA replication proteins was largely restricted to CAPAN2. Bar-graphs demonstrating the repression of representative genes are shown (Fig. 2D). One of the key determinants of mitotic gene expression is FOXM1 [41]. FOXM1 is both a transcriptional target of $\mathrm{RB} / \mathrm{E} 2 \mathrm{~F}$, and a direct target for protein stability by CDK4/6 [40]. By gene expression profiling FOXM1 repression was largely restricted to CAPAN2 cells; however, by RPPA analysis FOXM1 protein levels were reduced uniformly (Fig. 2E). These data suggest that there is a fundamental difference in the mechanisms underlying the repression of different classes of cell cycle genes, but that suppression of genes involved in DNA replication was particularly associated with durable response to CDK4/6 inhibition.

\section{Intrinsic aberrant regulation of Cyclin $\mathrm{E}$ is a key determinant of resistance to CDK4/6 inhibition}

In an attempt to decipher the mechanism underlying the specific resistance to $\mathrm{CDK} 4 / 6$ inhibition, we interrogated the expression of critical CDK and Cyclins that are important for progression through $\mathrm{G} 1 / \mathrm{S}$. These data demonstrated that certain genes are repressed irrespectively (e.g. Cyclin A2) (Fig. 3A). However, there was a consistent upregulation of Cyclin D1 in all models (Fig 3A). Additionally in PL45 and PL5 cells that are relatively resistant to $\mathrm{CDK} 4 / 6$ inhibition there was a reproducible upregulation of Cyclin E1 transcript (Fig
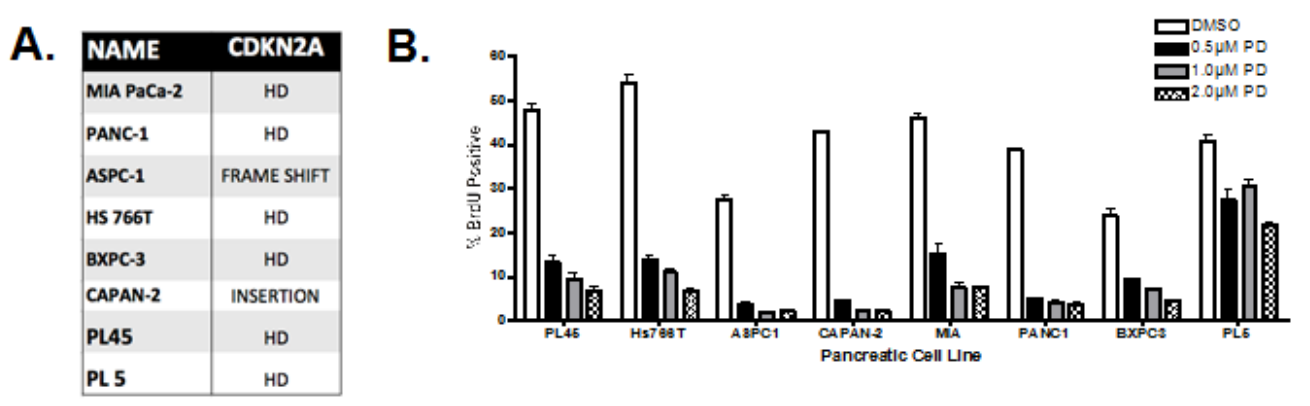

C.
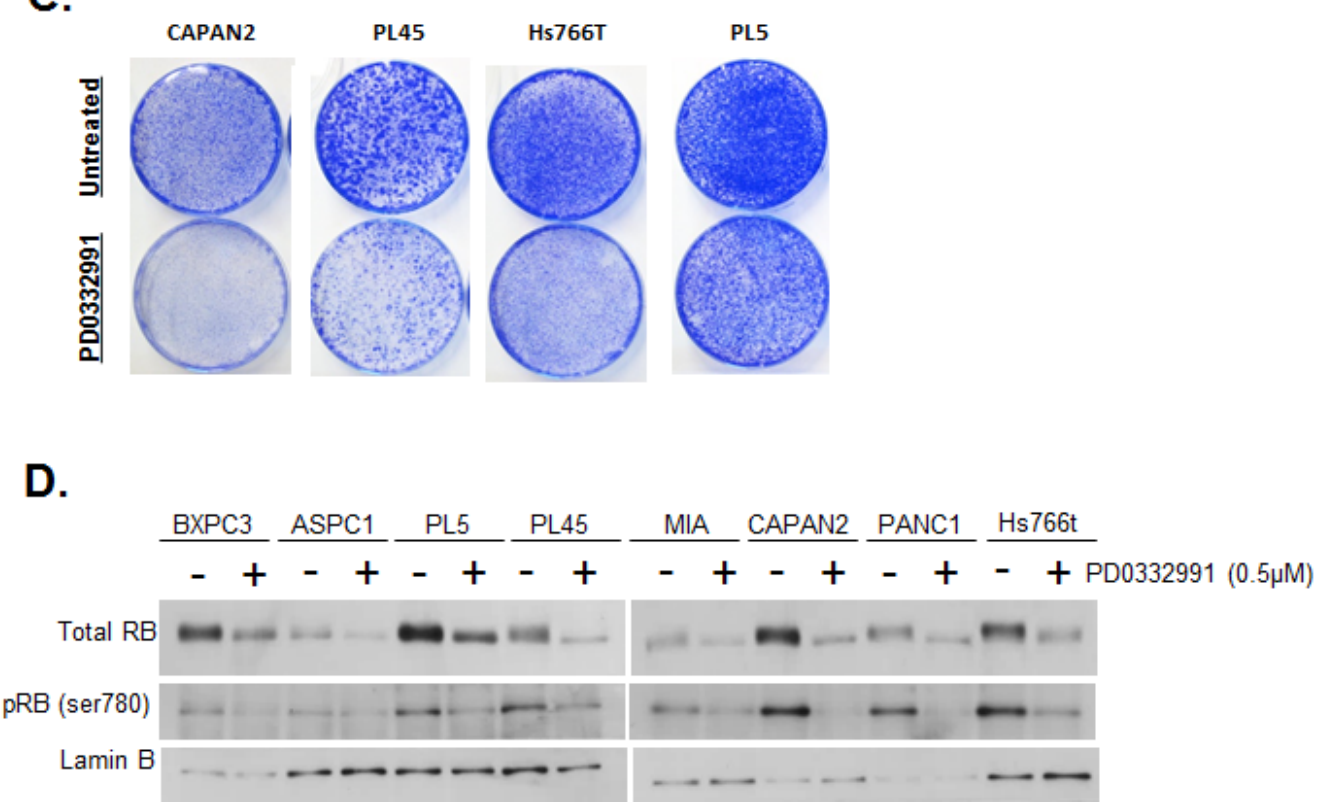

Figure1: PDA cell lines display differential responses to CDK4/6 inhibition. (A) Eight PDA cell lines were employed with documented deleterious mutations in the CDKN2A tumor suppressor. (B) Cells were treated with indicated concentrations of PD-0332991 $(0.5,1$, and $2 \mu \mathrm{M})$ for 24 hours. Cell cycle progression was quantified by BrdU incorporation as determined by flow cytometry. Data shown is from three independent experiments. (C) CDK4/6 effects on total RB and phospho-serine 780 were evaluated by immunoblotting. (D) Long-term responses to PD-0332991 in select PDA cell lines were assessed using crystal violet staining after 10 days of treatment with drug replenishment every three days. 
A.

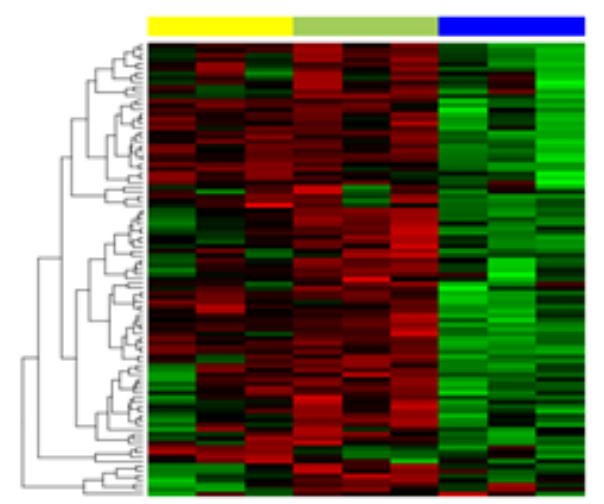

B.

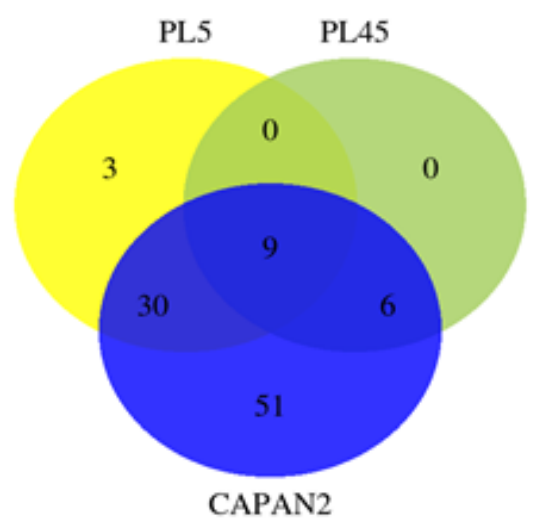

C.

\begin{tabular}{|l|c|c|}
\hline \multicolumn{1}{|c|}{ Gene Ontology } & $\begin{array}{c}\text { Commonto } \\
\text { multiplecell lines }\end{array}$ & $\begin{array}{c}\text { Repressed } \\
\text { CAPAN2 }\end{array}$ \\
\hline Mitosis & $1.99 \mathrm{E}-45$ & $5.56 \mathrm{E}-52$ \\
\hline M phase of mitotic cell cycle & $1.81 \mathrm{E}-45$ & $1.26 \mathrm{E}-51$ \\
\hline M phase & $1.90 \mathrm{E}-42$ & $4.02 \mathrm{E}-54$ \\
\hline DNA replication & 0.0026 & $1.02 \mathrm{E}-21$ \\
\hline DNA metabolic process & 0.0259 & $9.53 \mathrm{E}-18$ \\
\hline
\end{tabular}

D.

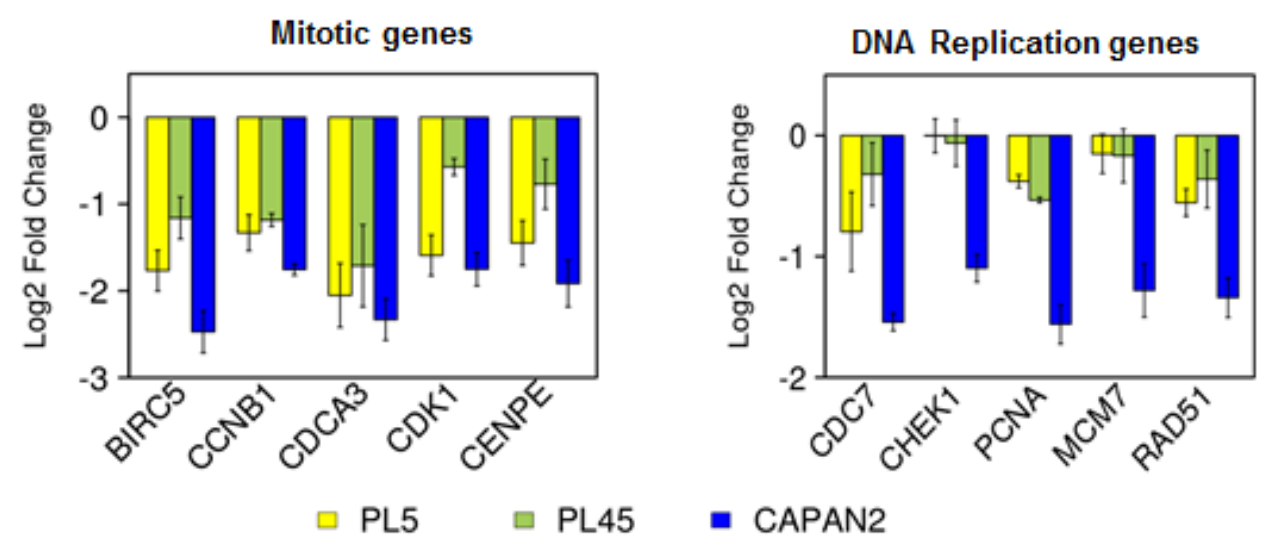

E.
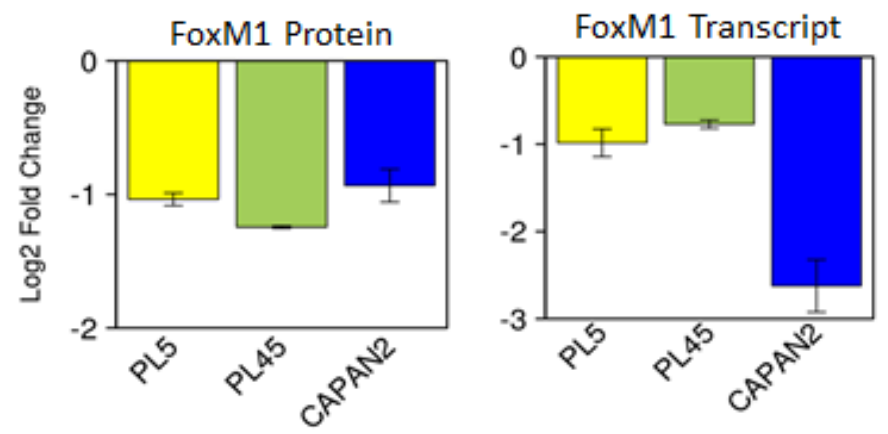

Figure 2: Gene expression profiling of $\mathrm{RB} / \mathrm{E} 2 \mathrm{~F}$ target genes reveals differential transcriptional repression. (A) Heatmap analysis of transcripts that are potently repressed by PD-0332991 in at least one cell model. (B) Venn diagrams demonstrating the overlap of genes that are repressed by at least two-fold $(p<0.05)$ in each cell line. $(C)$ Gene ontology analysis of genes repressed in multiple models vs. those repressed in CAPAN2. (D) Representative gene expression of genes involved in mitotic progression (left) and DNA replication replication (right). (E) RPPA and Gene expression analysis of FoxM1. 
3A). The induction of Cyclin D1 has been previously described in other models [32, 33]; however, the induction of Cyclin E1 is a unique observation in the setting of PDA. Therefore, the levels of Cyclin E1 were determined by immunoblotting across all cell lines (Fig. 3B). These data revealed that cyclin E1 induction was particularly apparent in multiple cell lines including PL5, MIAPACA2, PANC1 and HS766T. To determine the functional relevance of cyclin upregulation in PDA models exposed to PD0332991, RNAi was used to knockdown Cyclin D1 and Cyclin E1. Individually, both Cyclin D1 and Cyclin E1 knockdown inhibited cell cycle progression as determined by $\mathrm{BrdU}$ incorporation (Fig. 3C/D). In the case of Cyclin D1 depletion there was an additive effect on cell cycle progression in combination with PD-0332991. In contrast, Cyclin E1 deletion prevented virtually all BrdU incorporation in combination with PD-0332991. These data indicate that Cyclin E1 upregulation contributes to the observed resistance of PDA models to CDK4/6 inhibition, and suggests a unique feature of signaling that compromises the sensitivity to CDK4/6 inhibition in PDA models.

\section{CDK4/6 inhibition results in both antagonistic and additive responses with other anti-cancer therapies}

It is widely recognized that combination approaches to therapy will be required for the success of targeted agents in the treatment of pancreatic cancer. Given the modest response to CDK4/6 inhibitors we interrogated

A.
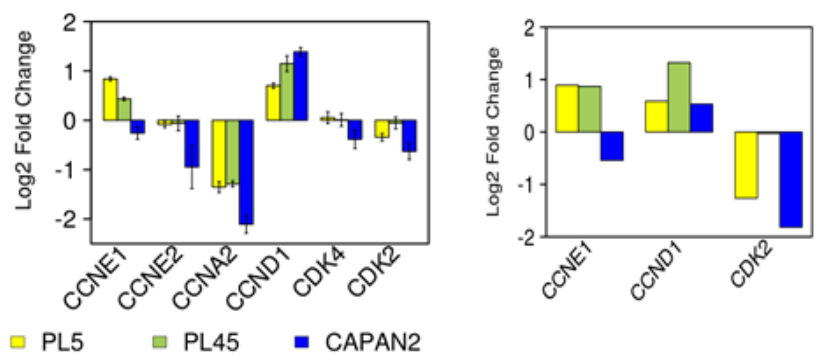

B.

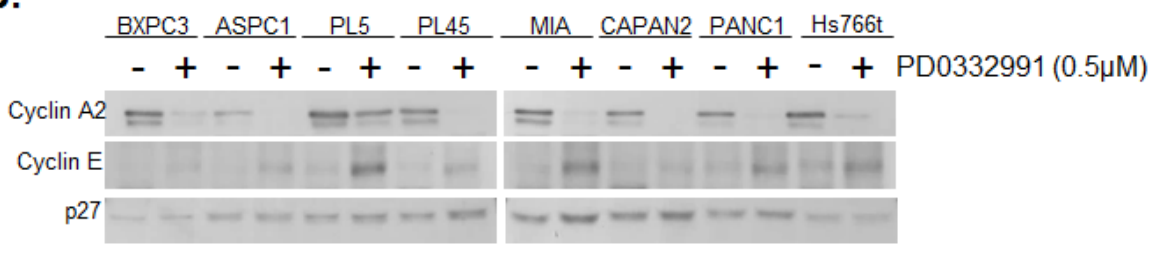

C.

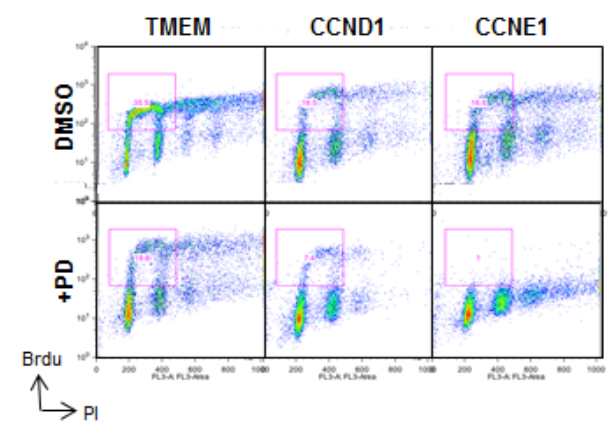

D.

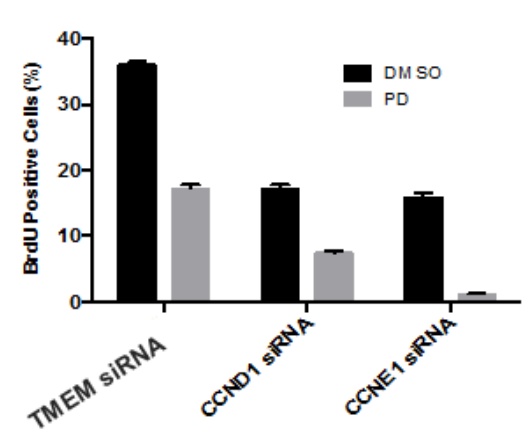

Figure 3: CDK4/6 inhibition induces aberrant expression of CCNE1 and CCND1. (A) Analysis of gene expression related to control over G1/S regulated CDK activity is shown from two different array platforms. (B) CCNE1 expression was evaluated by immunoblotting. (C) Cell cycle progression of PL5 cells was determined following knockdown of CCND1 or CCNE1 by RNAi in the presence or absence of $1 \mu \mathrm{M}$ PD-0332991. (D) Quantification of BrdU incorporation from three independent experiments. Data is expressed as percentage of BrdU positive cells, and a significant difference $(p<0.01)$ was observed between CCND1 and CCNE1 knockdown concurrent with PD-0332991 treatment versus knockdown alone in both PL-45 and PL-5. 
the impact of PD-0332991 on 304 anti-cancer compounds (supplemental tables). Drug screening was performed in PL45, PL5 and MIAPACA2 PDA models, which are relatively resistant to PD-0332991. Cells were treated singly with the drug library or with concurrent PD0332991. Cell survival was determined by CTG analysis and representative data is depicted in the scatter plots (Fig. 4A). To globally evaluate the response of select classes of drugs, heatmaps were generated plotting the log fraction of surviving cells to define the relative response (Fig. 4B). Antagonistic responses are drug combinations where CDK4/6 inhibitor protected cells from the other agent. We observed robust antagonism of specific chemotherapeutic drugs, PLK1 inhibitors, and other drugs specifically dependent on ongoing cell cycle progression for their mechanism of action (Fig. 4C, left panel). In contrast, additive effects were observed for MEK across a relatively broad range of compounds (Fig. 4B and C, middle). Similarly PI3K (e.g. GDC0941), MTOR (e.g. AZD0855), and dual PI3K/MTOR (e.g. GDC0980) inhibitors exhibited cooperative inhibition with PD-0332991 (Fig. 4B and $\mathrm{C}$, right). In all cases the overall impact of CDK4/6 inhibition was statistically significant across the drug class selected.

\section{Drug context specific effects of CDK4/6 inhibition on chemotherapies}

The drug screening indicated that CDK4/6 inhibition has the potential to antagonize the effect of various types of chemotherapies. We speculated that the cytostatic effect of CDK4/6 inhibition may represent the principle mechanism leading to a decreased efficacy of drugs targeting the mitotic machinery. As shown, PLK1 inhibitors were antagonized by co-treatment with PD0332991 (Fig. 5A). Since such drugs can have off-target effects, PLK1, which is an essential kinase during mitosis, was depleted (Fig. 5A). In absence of CDK4/6 inhibitors,
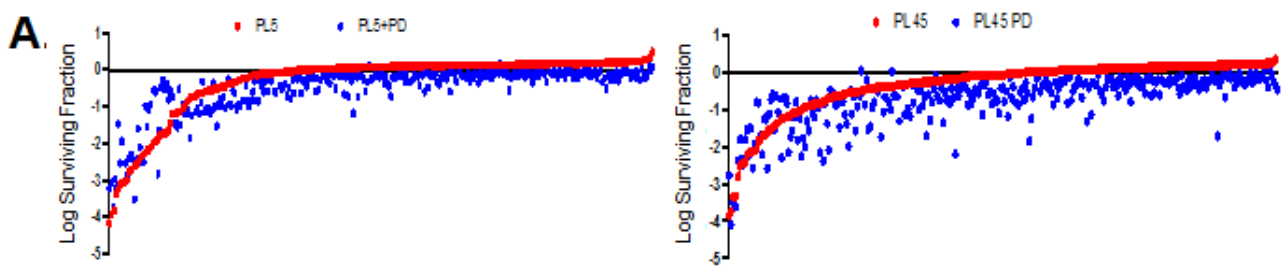

B.
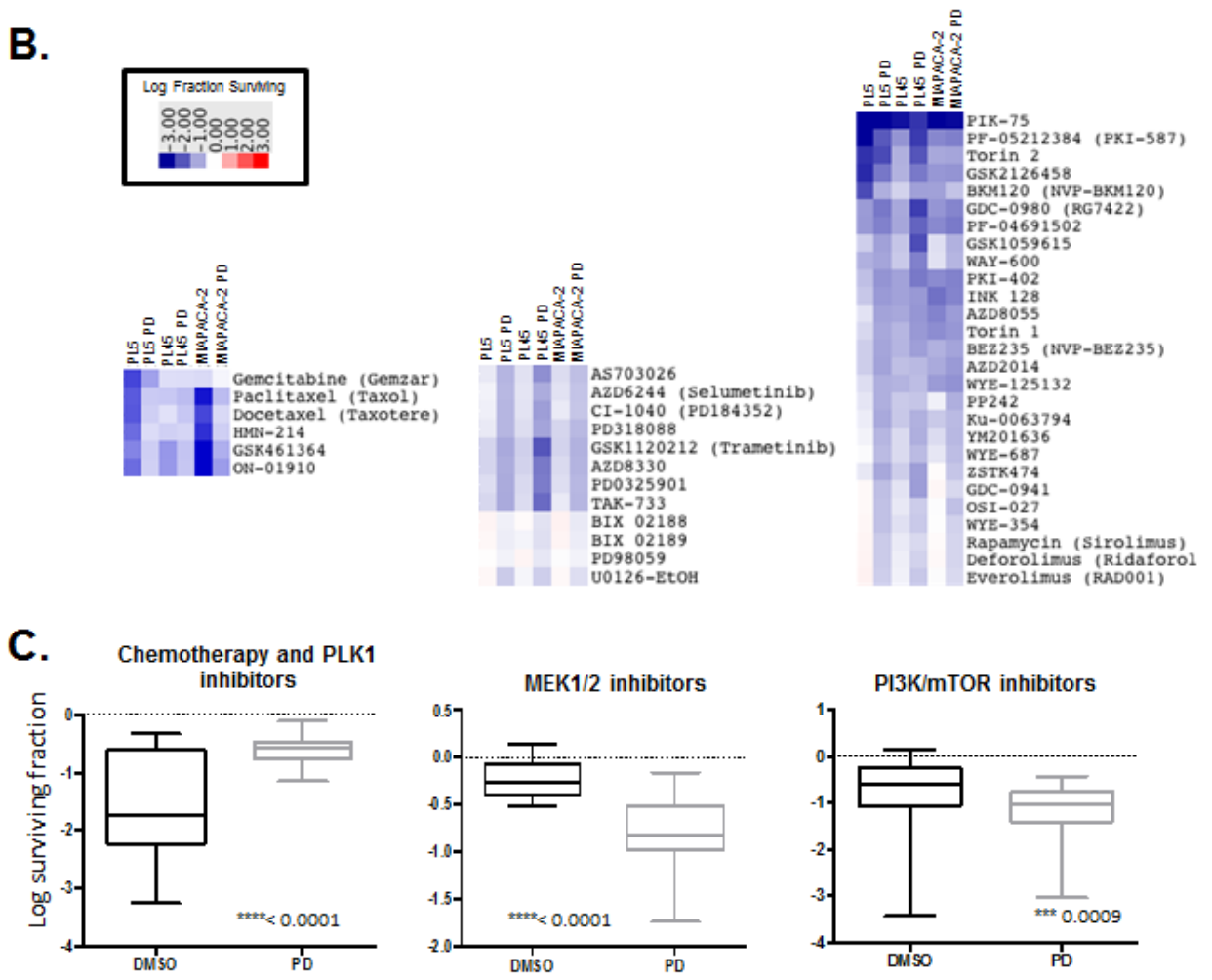

Figure 4: Drug screen for interaction with CDK4/6 inhibitor. (A) Scatter plots diagrams showing overall drug responses to drug screen by PL5, PL45 and MIAPACA2 in the presence or absence of $1 \mu \mathrm{M}$ PD-0332991. (B) Heatmaps displaying relative response to chemotherapeutics/PLK1 inhibitors (left), MEK inhibitors (middle) and PI3K/MTOR inhibitors (right) (C) Log surviving fraction chemotherapeutics/PLK1 inhibitors (left), MEK inhibitors (middle) and PI3K/MTOR inhibitors (right) for all cell lines. Average, 95\% confidence interval and $p$-value are shown. 
PLK1 inhibition led to significant reduction in viability, but in the presence of CDK4/6 inhibitor, this effect was significantly diminished. This finding suggested that even the modest cell cycle inhibition observed in PL5 and PL45 models will still impinge on the cytotoxic effects of antimitotic agents, such as docetaxel and paclitaxel that are present in the drug screen.

In addition to anti-mitotic drugs, PD-0332991 treatment significantly antagonized gemcitabine activity in drug screening. Since the anti-metabolites gemcitabine and 5-Fhoururacil (5-FU) are both used in the treatment of PDA, we specifically evaluated response to these drugs. Initially, we simply recapitulated the antagonism of Gemcitabine-mediated toxicity (Fig. 5B). These shortterm effects were re-affirmed in the analysis of overall cell survival by crystal violet analysis (Fig. 5C). In this setting, gemcitabine effectively killed the PDA cells; however, in the presence of PD-0332991 a fraction of cells survived. These findings contrasted with the observation for 5-FU, which although having limited effect, was not antagonized by CDK4/6 inhibition and in some lines there was evidence of cooperative effects (Fig. 5C). A likely basis for this differential response relates to the role of E2F target genes deoxycytidine kinase (DCK) and thymidylate synthase (TS). DCK is required to activate gemcitabine and cells exposed to PD-0332991 have reduced level of this protein (Fig. 5D). In contrast TS is the target for 5FU-mediated inhibition and reduced levels of TS are associated with increased drug sensitivity. In the PDA models, treatment with PD-0332991 suppressed
A.
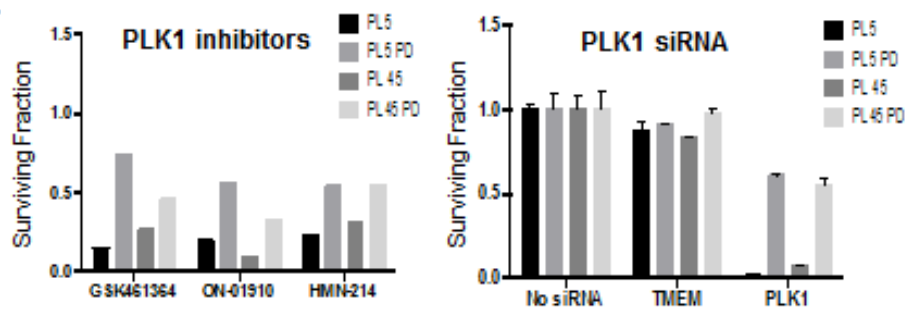

C.
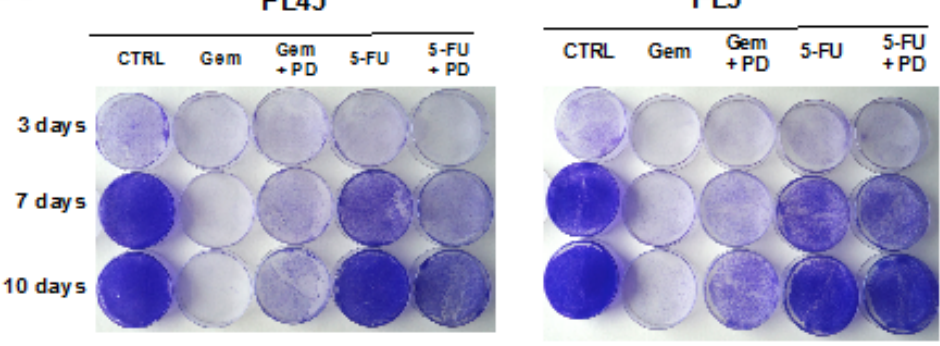

D.

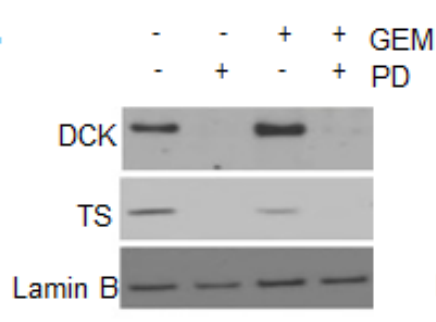

B.

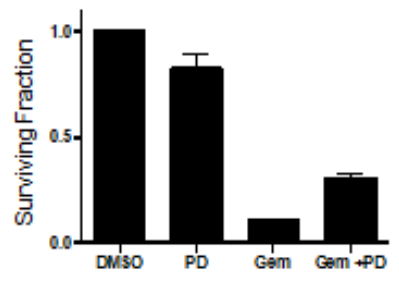

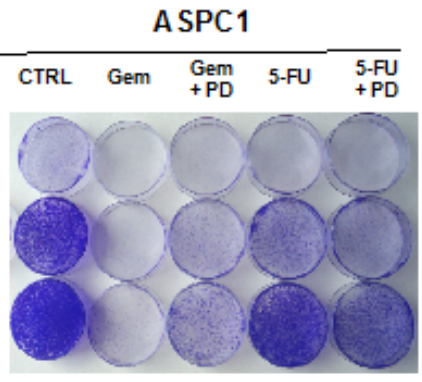

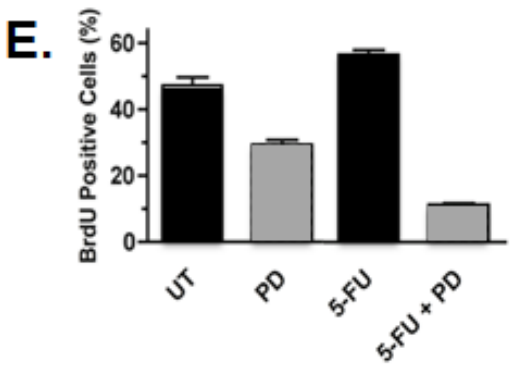

Figure 5: Drug specific effect of CDK4/6 inhibition on chemotherapy. (A) PL5 cells were either treated with PLK1 inhibitors or transfected with the indicated RNAi in the presence or absence of $1 \mu \mathrm{M}$ PD-0332991. At 72 hours post-treatment or transfection cell viability was measured by CTG assay. Results are expressed as the surviving fraction, and a significant difference of $\mathrm{p}<0.005$ was observed between co-treated with PD-0332991 compared to PLK1 inhibited alone. (B) PL-5 cells were treated with $5 \mu$ M gemcitabine as a single agent or in combination with PD-0332991 for 72 hours and viability assessed by CTG Assay. Results are expressed as the surviving fraction, and a significant difference of $\mathrm{p}<0.005$ was observed between co-treated with gemcitabine and PD-0332991 compared to gemcitabine treatment alone. (C) Long-Term responses to single agent or co-treatments with Gemcitabine $(1 \mu \mathrm{M})$ and 5 -FU $(25 \mu \mathrm{M})$ in the presence or absence of $1 \mu \mathrm{M}$ PD-0332991 was evaluated in PL-45, PL5 and ASPC1 cells by crystal violet. (D) Effects of CDK4/6 inhibition concurrent with either Gemcitabine or 5-FU on the DCK and TS protein was detected by immunoblotting. *Indicates the mobility of 5FU-TS adduct. (E) PL5 Cells were treated as indicated with PD-0332991 (1 $\mu \mathrm{M})$ or 5-FU $(25 \mu \mathrm{M})$. 
TS levels (Fig. 5D). Treatment with 5FU leads to a covalent bond with TS, and thus stoichiometric inhibition of TS is ostensibly easier to achieve. Consistent with this hypothesis, we observed additive effects between PD-0332991 and 5FU and the suppression of BrdU incorporation (Fig. 5E). Together, these findings indicate that while combination treatments of CDK4/6 inhibitor and chemotherapy can be antagonistic, there are specific conditions where additive responses can be identified based on mechanism of action.
A.
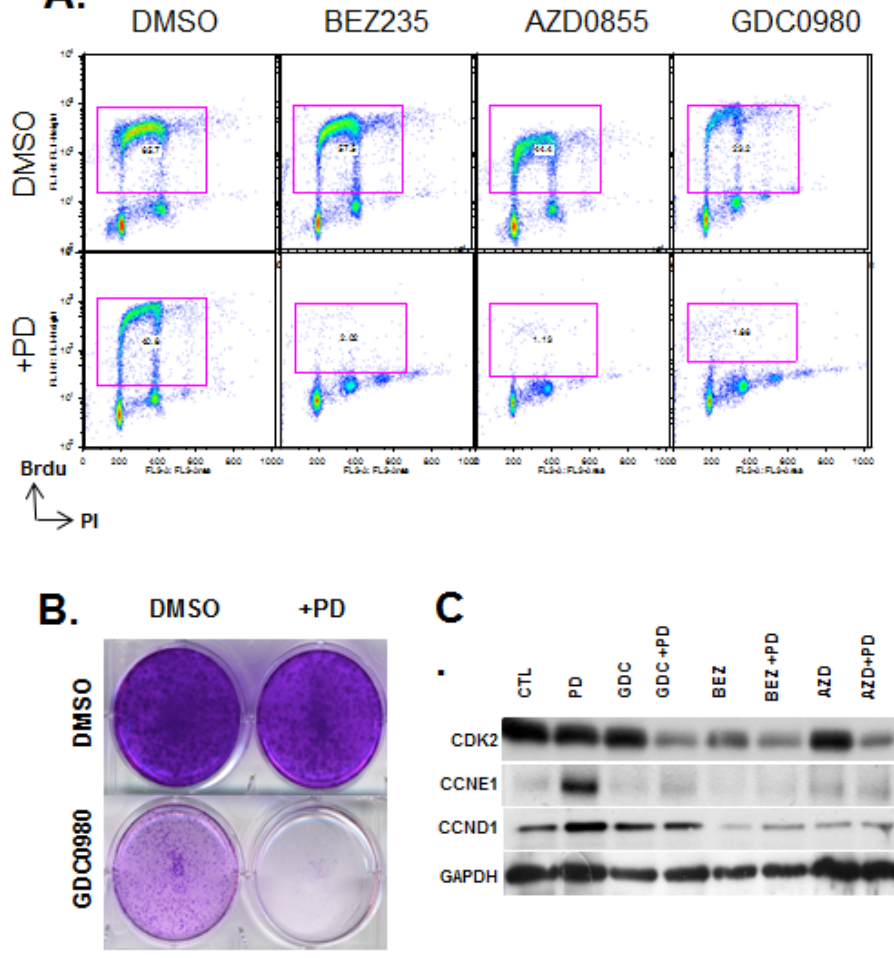

C

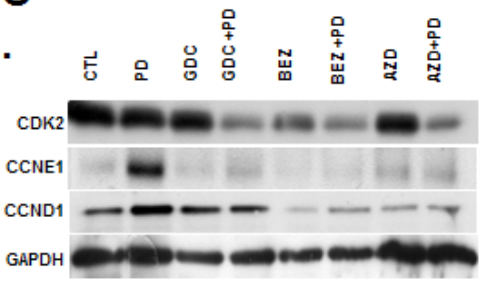

E.

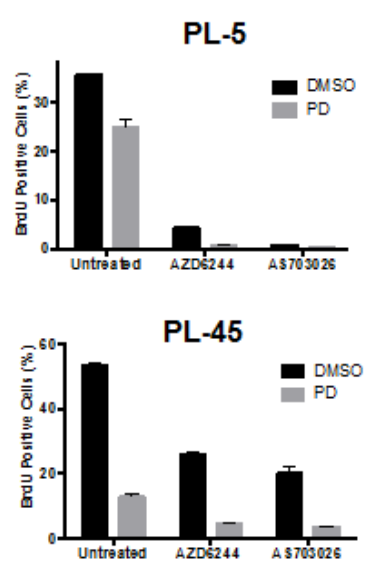

F.

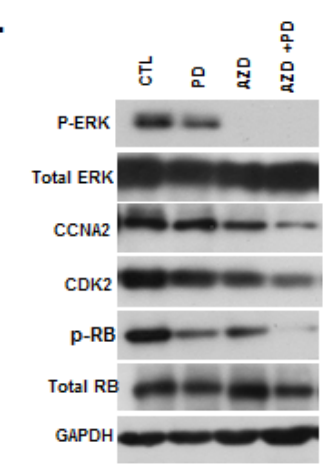

B.

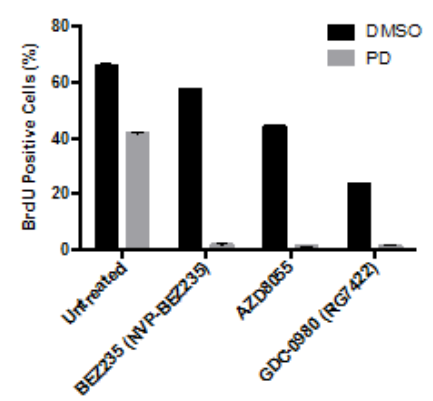

D.

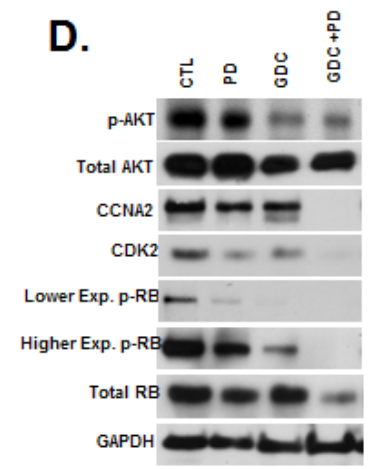

Figure 6: PI3K/MTOR and MEK inhibitors synergize with CDK4/6 inhibition. (A) PDA model PL5 was treated with $1 \mu$ M PI3K/MTOR inhibitors (BEZ235, AZD0855 and GDC0980) as a single agent or co-treated with 1 $\mu$ M PD-0332991. Cell cycle progression was determined by flow cytometry. (B) Quantification of BrdU incorporation from three independent experiments. Results are expressed as percentage of BrdU positive cells, and a significant difference of $\mathrm{p}<0.001$ was observed between co-treated versus PI3K inhibitor treatment alone. (C) Treatment with GDC0980 as a single agent and in combination with PD-0332991 was evaluated by crystal violet. (C) Effect of treatment with the PI3K/MTOR inhibitors alone and in the presence of PD-0332991 on the expression of the indicated proteins was determined by immunoblotting. (D) Effect of treatment with the PI3K/MTOR inhibitors alone and in the presence of PD-0332991 on the expression of the indicated proteins was determined by immunoblotting. (E) Quantification of the proliferative effects by CDK4/6 inhibitor concurrent with MEK1/2 inhibitor treatment assessed by Brdu incorporation. Results are expressed as percentage of BrdU Proliferating cells, and a significant difference of $\mathrm{p}<0.001$ was observed between co-treated and MEK1/2 inhibitor treatment alone. 


\section{Concurrent inhibition of CDK4/6 either with PI3K/mTOR or MEK inhibitors display cooperation in suppression of PDA proliferation}

As a whole, PI3K/MTOR inhibitors showed cooperative effects in concert with CDK4/6 inhibitor treatment assessed by viability assay in drug screening. In order to examine the mechanisms, BrdU incorporation was assessed after treatment with BEZ235, GDC0980 and AZD0855 in combination with CDK4/6 inhibitor (Fig 6A). Results indicate that CDK4/6 inhibitor in combination with these PI3K/MTOR inhibitors has a synergistic effect in suppression of cell cycle. PL5 cells that exhibit resistance to both the CDK4/6 inhibitor and $\mathrm{PI} 3 \mathrm{~K} / \mathrm{MTOR}$ inhibitors as single agents displayed a complete proliferative halt after treatment in both acute and long-term responses (Fig. 6B and C). This suppression of proliferation with co-treatment was associated with suppression of Cyclin D1 and Cyclin E1 expression that is observed with PD-0332991 (Fig. 6C). Additionally, there was suppression of additional critical cell cycle regulatory proteins including $\mathrm{CDK} 2$ and Cyclin $\mathrm{A}$, (Fig. 6D). In keeping with the suppression of multiple cyclins, although CDK4/6 inhibition has a profound effect on the phosphorylation of $\mathrm{RB}$, there is residual phosphorylation that was further suppressed in the context of co-treatment with PI3K/MTOR inhibitors (Fig. 6D). These data suggest that even low levels of RB phosphorylation can facilitate cell cycle progression, and provide the emphasis for full suppression of CDK-activity through complementary mechanisms.

In addition to PI3K/MTOR, MEK inhibitors also had additive effects in concert with CDK4/6 suppression. We demonstrated the cooperation at the level of cell cycle progression by BrdU incorporation and found that similar suppression of proliferation with the combination treatment (Fig. 6E). The biochemical effect of MEK inhibitors on RB phosphorylation paralleled the observation with PI3K/MTOR inhibition and revealing a similar basis for cooperation (Fig. 6F). Together, these findings suggest that PI3K/MTOR and MEK inhibitors could be particularly in combination with CDK4/6 inhibitors due to complementary mechanisms of action.

\section{DISCUSSION}

The treatment of pancreatic cancer is a particular challenge and new therapeutic approaches are urgently needed. One appealing means of intervention is to target specific genetic features of disease, and CDKN2A loss is one of the most common genetic alterations in PDA. Ostensibly, the loss of the kinase inhibitor results in aberrant CDK4/6 activation that could be targeted through the use of CDK4/6 inhibitors. Here we challenged this simple precept in preclinical models.
Interestingly, and contrary to multiple other tumor models, PDA models exhibited disparate responses to $\mathrm{CDK} 4 / 6$ inhibition that were not dependent on the canonical RB-pathways. In breast cancer, HCC, glioma, melanoma and other models, the response to CDK4/6 inhibition is simply dependent on the presence of RB [31, $33,51]$. Such tumors generally have lost CDKN2A, which provided the rationale for the study herein. Interestingly, within PDA there was a diversity of response to CDK4/6 suppression. Particularly, there were multiple models which exhibitary features associated with partial cell cycle inhibition, or relatively complete resistance. These findings are consistent with the work of others [52]. While it would be expected that there would be a full bypass of the requirement for CDK4/6 this was not observed, as RB phosphorylation remained largely dependent on CDK4/6. Additionally, there was significant suppression of a subset of E2F target genes. Interestingly, these genes are largely involved in mitosis, and are controlled by the DREAM and FOXM1 complexes that are ostensibly still effectively repressed in this setting [41]. In fact, we observed similar FOXM1 protein attenuation in all models studied, which is consistent with work demonstrating that FOXM1 protein accumulation is dependent on CDK4/6 activity [40]. However, the control of genes involved in DNA replication has emerged as a key RB-dependent function that is associated with terminal cell cycle arrest [53]. Therefore, the data here suggest that in select tumors models there is an uncoupling of these aspects of cell cycle control. In breast cancer and additional models PD0332991 results in robust suppression of the full spectrum of E2F target gents and therefore indicates that pancreatic cancer is somewhat unique in this aspect of cell cycle regulatory uncoupling.

The realization that such uncoupling can occur necessitated a highly focused analysis of CDK genes/ proteins that drive the $\mathrm{G} 1 / \mathrm{S}$ transition. Our group and others have shown that CDK4/6 inhibitors can lead to the accumulation of Cyclin D1 levels $[32,33]$. The basis of this response remains under study, but it could reflect more potent mitogenic signaling in the G1-phase of the cell cycle to stimulate the Cyclin D1 promoter. Importantly, we have observed this response in multiple models that exhibit a profound durable response to CDK4/6 inhibition; therefore, Cyclin D1 upregulation does not appear to be associated with resistance to PD-0332991. Surprisingly, our work revealed that resistant models exhibited an aberrant upregulation of Cyclin E. In general, CDK4/6 inhibition will reduce the level of Cyclin E transcripts; therefore, the upregulation in resistant models was particularly unexpected. Importantly, we could show that the levels of cyclin. DI and E contributed to the response and suggests that such proteins will modulate the durable response to CDK4/6 inhibition. Cyclin E-depletion was particularly synergistic with PD-0332991. These results agree with the overall concept that Cyclin E deregulation 
can contribute to bypass of CDK4/6 inhibitors [54].

In recognition that many PDA models did not harbor a particularly durable response to $\mathrm{CDK} 4 / 6$ inhibition, combination treatments were interrogated. This work revealed that CDK4/6 inhibition has complex interactions on the response to multiple agents. In particular, and consistent with others [55], CDK4/6 inhibition compromised the cytotoxicity of chemotherapeutic agents that primarily act via mitotic catastrophe including PLK1 inhibitors and taxanes. This result suggests the need to develop a rational metronomic schedule for drug treatment. In contrast, anti-metabolites are more difficult to predict as $\mathrm{RB} / \mathrm{E} 2 \mathrm{~F}$ regulate a host of genes that are drug targets or otherwise modify dNTP pools [56]. This aspect of $\mathrm{RB} / \mathrm{E} 2 \mathrm{~F}$ function is particularly important when evaluating anti-metabolites that would cooperate or be antagonized by CDK4/6 inhibition. It should be noted that in addition to the enzyme interrogated herein RB/ E2F modulates DHFR and RNRII levels that have highly significant effect on dNTP pools.

In contrast with chemotherapy, we observed highly reproducible additive effects across a relatively large panel of MEK and PI3K/MTOR inhibitors with CDK4/6 inhibition. These findings are particularly important since MEK and PI3K/MTOR inhibitors have been considered for the treatment of pancreatic cancer [57]. As shown here CDK4/6 inhibition can have relatively subtle effects on cell cycle and suppression of proliferation. In contrast, drug combinations yielded potent cytostatic response in all models tested. In the case of PI3K/MTOR the induction of Cyclin D1 and Cyclin E that occurs with CDK4/6 inhibition was completely blocked resulting in profound de-phosphorylation of RB. These finding are consistent with the work of others showing that cyclin D1 levels are under the control of MEK or MTOR signaling [58, 59]. Presumably, these data suggest that one of the "weaknesses" of pharmacological CDK4/6 inhibitors is compensatory or alternative regulators of RB phosphorylation. In the case of MEK and PI3K/ MTOR, there are well described mechanisms through which they limit the expression of Cyclins and suppress CDK activity. Ostensibly in many therapeutic contexts, these mechanisms of attenuating CDK-activity are NOT sufficient to halt cell cycle; however, due to the complementary mechanism of action such agents are particularly effective in concert with CDK4/6 inhibitors. Likely, a similar mechanism could underlie the profound clinical activity of CDK4/6 inhibitors with endocrine therapy; since in ER-positive breast cancer estrogen signaling is required for the expression of cyclin D1 and $\mathrm{E}$ $[60,61]$. Together, the work herein provides a roadmap for considering the clinical utilization of CDK4/6 inhibitors in the treatment of PDA.

\section{MATERIALS AND METHODS}

\section{Cell culture, chemicals and antibodies}

Human pancreatic cancer cell lines PL45, MIAPACA-2, PANC1, CAPAN2, BXPC3, HS 766T, ASPC1, PL5 were purchased from the American Type Culture Collection (ATCC). All cells except for MIAPACA2 were cultured in DMEM supplemented with $10 \%$ fetal bovine serum and antibiotics. MIAPACA2 cells were grown in DMEM with fetal bovine serum and horse serum to a final concentration of $10 \%$ and $2.5 \%$ respectively plus antibiotics. Drugs used in this study were purchased from Selleck Chemicals. Compounds were diluted in DMSO to $5 \mathrm{mM}$ stock concentrations. PD0332991 was employed at a concentration range of 0.5-2 $\mu \mathrm{M}$. Drugs screen was performed at $2.5 \mu \mathrm{M}$. Antibodies against CDK2, CCNE1, CCNA2, GAPDH, total ERK, p-ERK, lamin B, DCK, TS and p27 were purchased from Santa Cruz biotechnology. While, antibodies against total RB, p-RB(780), total Akt, p-Akt (ser473) were purchased from Cell signaling. Cyclin D1 (AB3) was from NeoMarkers.

\section{Drug Screen}

A library of 304 drugs from Selleck Chemicals was used for drug screening. Cells were grown in 96well plates at 2500 cell per well. Subsequent to plating, cell were treated with $1 \mu \mathrm{M}$ PD-0332991 or DMSO for 24 hours at $37^{\circ}$ and $5.0 \mathrm{CO}_{2}$. The next day, cells were treated with the drug library to final concentration of $2.5 \mathrm{uM}$, and incubated at $37^{\circ}$ and $5.0 \mathrm{CO}_{2}$ for 72 hours. Following treatment, viability was assessed using Celltiter Glo(Promega). The relative fluorescence units were detected and analyzed by a BIOTEK plate reader and Gen5 software. Data analysis was performed using Drug-decode macro (developed by David Haan, UT Southwestern).

\section{Flow cytometry}

Cell were trypsinized and fixed in $70 \%$ Ethanol post a 2 hour incubation with Brdu labeling solution(Invitrogen). Fixed cells were incubated in $2 \mathrm{M} \mathrm{HCl}$ with $0.3 \mathrm{mg} / \mathrm{ml}$ pepsin solution for 30 minutes followed by addition of $0.1 \mathrm{M}$ sodium tetraborate solution( $\mathrm{pH}$ 8.5). After acid neutralization, cells were washed twice with IFA(10mM HEPES(pH 7.4), 25 mM NACI, 4\% FBS) buffer. Cells were then incubated with FITC labeled anti-Brdu(BD Pharmingen) at 1:10 dilution for $30 \mathrm{~min}$ at room temperature. After Brdu labeling, Propidium iodine $(20 \mathrm{ug} / \mathrm{ml})$ and RNAse $(4 \mathrm{ug} / \mathrm{ml})$ 
was added and incubated for 15 minutes in Dark. BrdU incorporation was assessed using a Facscalibur Instrument and data was analyzed using FlowJo .

\section{Western blot analysis and reverse phase protein array analysis}

Pancreatic cell lines were lysed in RIPA buffer $(10 \%$ NP-40 substitute, 1\% SDS, 500mM Tris-HCI(pH 7.4), $1.5 \mathrm{M} \mathrm{NaCI}, 5 \%$ sodium doxycholate, $10 \mathrm{mM}$ EDTA) containing both complete protease inhibitor cocktail tablets (Roche) and phosphatases inhibitors (Roche). Protein concentrations were subsequently measured with the BCA protein assay DC ${ }^{\mathrm{tm}}$ Protein Assay (BIORAD) using manufacture's protocol. These samples were resolved on SDS polyacrylamide gels and electroblotted to Immobilon-P Transfer Membrane. Membranes were washed with wash buffer $(0.1 \%$ Tween- $20 / 1 \mathrm{x}$ saline $)$. Followed by incubation with blocking solution $(5 \%$ BSA, $0.1 \%$ Tween-20; saline). Primary antibodies (1/500 dilution) at $4^{\circ} \mathrm{C}$ overnight. The membranes were then washed in were applent buffer and incubated with horseradish peroxidase conjugated secondary antibodies (Jackson ImmunoResearch). Antibody detection was performed with an enhanced chemiluminescence reaction (SuperSignal) as directed by manufacture.

Protein lysates were prepared from cell treated with vehicle or $1 \mu \mathrm{M}$ PD-0332991 for 48 hours. Preparation from RPPA were as directed by the MD Anderson RPPA shared service, and the analysis of the signals were performed using their standardized procedures. The difference in normalized log protein values are presented in the analysis.

\section{Short-term and long-term treatments of in vitro models}

For short term treatments, pancreatic cell lines were seeded at $5 \times 10^{4}$ cell/well in 6 well plate and left to adhere for 3 hours at $37^{\circ} \mathrm{C}$. Cells were then treated with individual drug or drug combinations at $1 \mathrm{uM}$ concentrations and incubated for 24-72 hours. For longterm experiment, cell were seeded at $5 \times 10^{3}$ cell/ well and drugs were replenished every 3 days for 10 days. Following long term studies, they were assessed by cystal violet.

\section{Transfection of siRNA}

Pancreatic cell lines were seeded in a 6-well plate at a desity of $5 \times 10^{5}$ cells per well and transfected with siRNA against either CCND1 (Santa Cruz biotechnology), CCNE1 (SMARTpool: Accell CCNE1 siRNA; Dharmacon) and PLK1(SMARTpool: Accell PLK1
siRNA; Dharmacon) at a final concentration 50nmol/L with Lipofectamine RNAiMAX(Invitrogen) according to manufacture's instructions. Transfections with a control sRNA(TMEM) served as a negative control.

\section{Gene Expression analysis}

Cells were treated with vehicle or $1 \mu \mathrm{M}$ PD-0332991 for 48 hours (RBTARGET) or 120 hours (Agilent Array). The RBTARGET array is a custom Affymetrix Gene Chip that encompasses genes regulated by $\mathrm{RB}$ and highly correlated genes together with additional gene for normalization, full list of the probes on the RBTARGET platform are provided in the supplemental data. Total RNA was recovered and hybridized using standard procedures. Data analysis was performed on normalized data. To define differentially expressed genes, a cutoff of 2-fold and $\mathrm{p}<0.05$ was utilized.

\section{ACKNOWLEDGEMENTS}

The authors thank their colleagues for insightful discussion, editorial assistance and technical support for this work. Dr. Matias Valeschi, Mr. David Haan, Dr. Jeffry Dean and Ms. Uthra Balaji assisted in generation of specific data for the study.

\section{REFERENCES}

1. Paulson AS, Tran Cao HS, Tempero MA and Lowy AM. Therapeutic advances in pancreatic cancer. Gastroenterology. 2013; 144(6):1316-1326.

2. Kleger A, Perkhofer L and Seufferlein T. Smarter drugs emerging in pancreatic cancer therapy. Annals of oncology : official journal of the European Society for Medical Oncology / ESMO. 2014.

3. Almhanna K and Philip PA. Defining new paradigms for the treatment of pancreatic cancer. Curr Treat Options Oncol. 12(2):111-125.

4. Philip PA, Mooney M, Jaffe D, Eckhardt G, Moore M, Meropol N, Emens L, O’Reilly E, Korc M, Ellis L, Benedetti J, Rothenberg M, Willett C, Tempero M, Lowy A, Abbruzzese J, et al. Consensus report of the national cancer institute clinical trials planning meeting on pancreas cancer treatment. J Clin Oncol. 2009; 27(33):5660-5669.

5. Cowan RW and Maitra A. Genetic progression of pancreatic cancer. Cancer journal. 2014; 20(1):80-84.

6. Yachida S and Iacobuzio-Donahue CA. Evolution and dynamics of pancreatic cancer progression. Oncogene. 2013; 32(45):5253-5260.

7. Kanda M, Matthaei H, Wu J, Hong SM, Yu J, Borges M, Hruban RH, Maitra A, Kinzler K, Vogelstein B and Goggins M. Presence of somatic mutations in most earlystage pancreatic intraepithelial neoplasia. Gastroenterology. 
2012; 142(4):730-733 e739.

8. Chu TM. Molecular diagnosis of pancreas carcinoma. J Clin Lab Anal. 1997; 11(4):225-231.

9. Witkiewicz AK, Knudsen KE, Dicker AP and Knudsen ES. The meaning of p16(ink4a) expression in tumors: functional significance, clinical associations and future developments. Cell Cycle. 2011; 10(15):2497-2503.

10. Bardeesy N, Aguirre AJ, Chu GC, Cheng KH, Lopez LV, Hezel AF, Feng B, Brennan C, Weissleder R, Mahmood U, Hanahan D, Redston MS, Chin L and Depinho RA. Both p16(Ink4a) and the p19(Arf)-p53 pathway constrain progression of pancreatic adenocarcinoma in the mouse. Proc Natl Acad Sci U S A. 2006; 103(15):5947-5952.

11. Serrano M, Lin AW, McCurrach ME, Beach D and Lowe $\mathrm{SW}$. Oncogenic ras provokes premature cell senescence associated with accumulation of p53 and p16INK4a. Cell. 1997; 88(5):593-602.

12. Narita M, Nunez S, Heard E, Lin AW, Hearn SA, Spector DL, Hannon GJ and Lowe SW. Rb-mediated heterochromatin formation and silencing of E2F target genes during cellular senescence. Cell. 2003; 113(6):703716.

13. Herreros-Villanueva M, Hijona E, Cosme A and Bujanda L. Mouse models of pancreatic cancer. World journal of gastroenterology : WJG. 2012; 18(12):1286-1294.

14. Serrano M, Gomez-Lahoz E, DePinho RA, Beach D and Bar-Sagi D. Inhibition of ras-induced proliferation and cellular transformation by p16INK4. Science. 1995; 267(5195):249-252.

15. Calbo J, Marotta M, Cascallo M, Roig JM, Gelpi JL, Fueyo $\mathrm{J}$ and Mazo A. Adenovirus-mediated wt-p16 reintroduction induces cell cycle arrest or apoptosis in pancreatic cancer. Cancer gene therapy. 2001; 8(10):740-750.

16. Chen F, Li Y, Lu Z, Gao J and Chen J. Adenovirusmediated Ink4a/ARF gene transfer significantly suppressed the growth of pancreatic carcinoma cells. Cancer Biol Ther. 2005; 4(12):1348-1354.

17. Lukas J, Sorensen CS, Lukas C, Santoni-Rugiu E and Bartek J. p16INK4a, but not constitutively active pRb, can impose a sustained G1 arrest: molecular mechanisms and implications for oncogenesis. Oncogene. 1999; 18(27):3930-3935.

18. Xiong $\mathrm{Y}$, Zhang $\mathrm{H}$ and Beach D. Subunit rearrangement of the cyclin-dependent kinases is associated with cellular transformation. Genes Dev. 1993; 7(8):1572-1583.

19. Pavletich NP. Mechanisms of cyclin-dependent kinase regulation: structures of Cdks, their cyclin activators, and Cip and INK4 inhibitors. Journal of molecular biology. 1999; 287(5):821-828.

20. Russo AA, Tong L, Lee JO, Jeffrey PD and Pavletich NP. Structural basis for inhibition of the cyclin-dependent kinase Cdk6 by the tumour suppressor p16INK4a. Nature. 1998; 395(6699):237-243.

21. Malumbres M and Barbacid M. Is Cyclin D1-CDK4 kinase a bona fide cancer target? Cancer Cell. 2006; 9(1):2-4.

22. Serrano M, Hannon GJ and Beach D. A new regulatory motif in cell-cycle control causing specific inhibition of cyclin D/CDK4. Nature. 1993; 366(6456):704-707.

23. Koh J, Enders GH, Dynlacht BD and Harlow E. Tumourderived p16 alleles encoding proteins defective in cell-cycle inhibition. Nature. 1995; 375(6531):506-510.

24. Zuo L, Weger J, Yang Q, Goldstein AM, Tucker MA, Walker GJ, Hayward N and Dracopoli NC. Germline mutations in the p16INK4a binding domain of CDK4 in familial melanoma. Nat Genet. 1996; 12(1):97-99.

25. Bartkova J, Lukas J, Guldberg P, Alsner J, Kirkin AF, Zeuthen $J$ and Bartek J. The p16-cyclin D/Cdk4-pRb pathway as a functional unit frequently altered in melanoma pathogenesis. Cancer Res. 1996; 56(23):5475-5483.

26. Lukas J, Parry D, Aagaard L, Mann DJ, Bartkova J, Strauss M, Peters G and Bartek J. Retinoblastoma-proteindependent cell-cycle inhibition by the tumour suppressor p16. Nature. 1995; 375(6531):503-506.

27. Shapiro GI, Edwards CD, Kobzik L, Godleski J, Richards W, Sugarbaker DJ and Rollins BJ. Reciprocal Rb inactivation and p16INK4 expression in primary lung cancers and cell lines. Cancer Res. 1995; 55(3):505-509.

28. Kaye FJ. RB and cyclin dependent kinase pathways: defining a distinction between RB and p16 loss in lung cancer. Oncogene. 2002; 21(45):6908-6914.

29. Fry DW, Harvey PJ, Keller PR, Elliott WL, Meade M, Trachet E, Albassam M, Zheng X, Leopold WR, Pryer NK and Toogood PL. Specific inhibition of cyclin-dependent kinase 4/6 by PD 0332991 and associated antitumor activity in human tumor xenografts. Mol Cancer Ther. 2004; 3(11):1427-1438.

30. Toogood PL, Harvey PJ, Repine JT, Sheehan DJ, VanderWel SN, Zhou H, Keller PR, McNamara DJ, Sherry D, Zhu T, Brodfuehrer J, Choi C, Barvian MR and Fry DW. Discovery of a potent and selective inhibitor of cyclindependent kinase 4/6. Journal of medicinal chemistry. 2005; 48(7):2388-2406.

31. Michaud K, Solomon DA, Oermann E, Kim JS, Zhong WZ, Prados MD, Ozawa T, James CD and Waldman T. Pharmacologic inhibition of cyclin-dependent kinases 4 and 6 arrests the growth of glioblastoma multiforme intracranial xenografts. Cancer Res. 2010; 70(8):3228-3238.

32. Rivadeneira DB, Mayhew CN, Thangavel C, Sotillo E, Reed CA, Grana X and Knudsen ES. Proliferative suppression by CDK4/6 inhibition: complex function of the retinoblastoma pathway in liver tissue and hepatoma cells. Gastroenterology. 2010; 138(5):1920-1930.

33. Dean JL, Thangavel C, McClendon AK, Reed CA and Knudsen ES. Therapeutic CDK4/6 inhibition in breast cancer: key mechanisms of response and failure. Oncogene. 2010; 29(28):4018-4032.

34. Markey MP, Angus SP, Strobeck MW, Williams SL, Gunawardena RW, Aronow BJ and Knudsen ES. Unbiased 
analysis of RB-mediated transcriptional repression identifies novel targets and distinctions from E2F action. Cancer Res. 2002; 62(22):6587-6597.

35. Dean JL, McClendon AK, Hickey TE, Butler LM, Tilley WD, Witkiewicz AK and Knudsen ES. Therapeutic response to CDK4/6 inhibition in breast cancer defined by ex vivo analyses of human tumors. Cell Cycle. 11(14):27562761 .

36. Dean JL, McClendon AK and Knudsen ES. Modification of the DNA damage response by therapeutic CDK4/6 inhibition. J Biol Chem.

37. McClendon AK, Dean JL, Rivadeneira DB, Yu JE, Reed CA, Gao E, Farber JL, Force T, Koch WJ and Knudsen ES. CDK4/6 inhibition antagonizes the cytotoxic response to anthracycline therapy. Cell Cycle. 11(14):2747-2755.

38. Konecny GE, Winterhoff B, Kolarova T, Qi J, Manivong K, Dering J, Yang G, Chalukya M, Wang HJ, Anderson L, Kalli KR, Finn RS, Ginther C, Jones S, Velculescu VE, Riehle D, et al. Expression of p16 and retinoblastoma determines response to CDK4/6 inhibition in ovarian cancer. Clin Cancer Res. 17(6):1591-1602.

39. Finn RS, Dering J, Conklin D, Kalous O, Cohen DJ, Desai AJ, Ginther C, Atefi M, Chen I, Fowst C, Los G and Slamon DJ. PD 0332991, a selective cyclin D kinase 4/6 inhibitor, preferentially inhibits proliferation of luminal estrogen receptor-positive human breast cancer cell lines in vitro. Breast Cancer Res. 2009; 11(5):R77.

40. Anders L, Ke N, Hydbring P, Choi YJ, Widlund HR, Chick JM, Zhai H, Vidal M, Gygi SP, Braun P and Sicinski P. A systematic screen for CDK4/6 substrates links FOXM1 phosphorylation to senescence suppression in cancer cells. Cancer Cell. 2011; 20(5):620-634.

41. Sadasivam S, Duan S and DeCaprio JA. The MuvB complex sequentially recruits B-Myb and FoxM1 to promote mitotic gene expression. Genes Dev. 2012; 26(5):474-489.

42. Leonard JP, LaCasce AS, Smith MR, Noy A, Chirieac LR, Rodig SJ, Yu JQ, Vallabhajosula S, Schoder H, English P, Neuberg DS, Martin P, Millenson MM, Ely SA, Courtney $\mathrm{R}$, Shaik N, et al. Selective CDK4/6 inhibition with tumor responses by PD0332991 in patients with mantle cell lymphoma. Blood. 119(20):4597-4607.

43. Dickson MA, Tap WD, Keohan ML, D'Angelo SP, Gounder MM, Antonescu CR, Landa J, Qin LX, Rathbone DD, Condy MM, Ustoyev Y, Crago AM, Singer S and Schwartz GK. Phase II trial of the CDK4 inhibitor PD0332991 in patients with advanced CDK4-amplified well-differentiated or dedifferentiated liposarcoma. J Clin Oncol. 2013; 31(16):2024-2028.

44. Schwartz GK, LoRusso PM, Dickson MA, Randolph SS, Shaik MN, Wilner KD, Courtney R and O’Dwyer PJ. Phase I study of PD 0332991, a cyclin-dependent kinase inhibitor, administered in 3-week cycles (Schedule 2/1). Br J Cancer. 2011; 104(12):1862-1868.

45. Flaherty KT, Lorusso PM, Demichele A, Abramson
VG, Courtney R, Randolph SS, Shaik MN, Wilner KD, O'Dwyer PJ and Schwartz GK. Phase I, dose-escalation trial of the oral cyclin-dependent kinase 4/6 inhibitor PD 0332991, administered using a 21-day schedule in patients with advanced cancer. Clin Cancer Res. 2012; 18(2):568576.

46. Lange CA and Yee D. Killing the second messenger: targeting loss of cell cycle control in endocrine-resistant breast cancer. Endocr Relat Cancer. 2011; 18(4):C19-24.

47. Thangavel C, Dean JL, Ertel A, Knudsen KE, Aldaz CM, Witkiewicz AK, Clarke R and Knudsen ES. Therapeutically activating RB: reestablishing cell cycle control in endocrine therapy-resistant breast cancer. Endocr Relat Cancer. 2011; 18(3):333-345.

48. Guha M. Blockbuster dreams for Pfizer's CDK inhibitor. Nature biotechnology. 2013; 31(3):187.

49. Dickson MA. Molecular Pathways: CDK4 Inhibitors for Cancer Therapy. Clin Cancer Res. 2014; 20(13):3379-3383.

50. Rocca A, Farolfi A, Bravaccini S, Schirone A and Amadori D. Palbociclib (PD 0332991) : targeting the cell cycle machinery in breast cancer. Expert opinion on pharmacotherapy. 2014; 15(3):407-420.

51. Kwong LN, Costello JC, Liu H, Jiang S, Helms TL, Langsdorf AE, Jakubosky D, Genovese G, Muller FL, Jeong JH, Bender RP, Chu GC, Flaherty KT, Wargo JA, Collins JJ and Chin L. Oncogenic NRAS signaling differentially regulates survival and proliferation in melanoma. Nature medicine. 2012; 18(10):1503-1510.

52. Liu F and Korc M. Cdk4/6 inhibition induces epithelialmesenchymal transition and enhances invasiveness in pancreatic cancer cells. Mol Cancer Ther. 2012; 11(10):2138-2148.

53. Chicas A, Wang X, Zhang C, McCurrach M, Zhao Z, Mert O, Dickins RA, Narita M, Zhang M and Lowe SW. Dissecting the unique role of the retinoblastoma tumor suppressor during cellular senescence. Cancer Cell. 2010; 17(4):376-387.

54. Caldon CE, Sergio CM, Kang J, Muthukaruppan A, Boersma MN, Stone A, Barraclough J, Lee CS, Black MA, Miller LD, Gee JM, Nicholson RI, Sutherland RL, Print CG and Musgrove EA. Cyclin E2 overexpression is associated with endocrine resistance but not insensitivity to CDK2 inhibition in human breast cancer cells. Mol Cancer Ther. 2012; 11(7):1488-1499.

55. Roberts PJ, Bisi JE, Strum JC, Combest AJ, Darr DB, Usary JE, Zamboni WC, Wong KK, Perou CM and Sharpless NE. Multiple roles of cyclin-dependent kinase 4/6 inhibitors in cancer therapy. J Natl Cancer Inst. 2012; 104(6):476-487.

56. Angus SP, Wheeler LJ, Ranmal SA, Zhang X, Markey MP, Mathews CK and Knudsen ES. Retinoblastoma tumor suppressor targets dNTP metabolism to regulate DNA replication. J Biol Chem. 2002; 277(46):44376-44384.

57. Infante JR, Somer BG, Park JO, Li CP, Scheulen ME, Kasubhai SM, Oh DY, Liu Y, Redhu S, Steplewski K and 
Le N. A randomised, double-blind, placebo-controlled trial of trametinib, an oral MEK inhibitor, in combination with gemcitabine for patients with untreated metastatic adenocarcinoma of the pancreas. Eur J Cancer. 2014.

58. Leontieva OV and Blagosklonny MV. CDK4/6-inhibiting drug substitutes for $\mathrm{p} 21$ and $\mathrm{p} 16$ in senescence: duration of cell cycle arrest and MTOR activity determine geroconversion. Cell Cycle. 2013; 12(18):3063-3069.

59. Leontieva OV, Demidenko $\mathrm{ZN}$ and Blagosklonny MV. MEK drives cyclin D1 hyperelevation during geroconversion. Cell death and differentiation. 2013; 20(9):1241-1249.

60. Palbociclib ups PFS in HER2-/ER+ breast cancer. Cancer Discov. 2014; 4(6):624-625.

61. Musgrove EA and Sutherland RL. Biological determinants of endocrine resistance in breast cancer. Nat Rev Cancer. 2009; 9(9):631-643. 